\title{
A teoria das representações sociais como referencial didático-metodológico de pesquisa no campo das ciências humanas e sociais aplicadas
}

\section{The theory of social representations as a teaching- methodology referenceof research in the field of applied social sciences and humanities}

\author{
Marcos Pereira dos Santos ${ }^{*}$
}

\begin{abstract}
Resumo: Este artigo tem como principal objetivo efetuar reflexões acerca da Teoria das Representações Sociais (TRS) de Serge Moscovici como referencial didático-metodológico de pesquisa no campo das Ciências Humanas e Sociais Aplicadas. Para tanto, inicialmente são apresentadas algumas definições conceituais gerais que gravitam em torno da palavra representação(ões), bem como uma breve visão panorâmica da Teoria das Representações Sociais. Em seguida, busca-se tecer comentários sobre a abordagem estrutural (ou do núcleo central) de Jean-Claude Abric como suporte teórico e metodológico das representações sociais. Por fim, trazemos à discussão questões concernentes à utilização da Teoria das Representações Sociais no desenvolvimento de pesquisas científicas e sua importância na atualidade. O estudo realizado apontou que a Teoria das Representações Sociais configura-se como um importante instrumento didático-metodológico de pesquisa científica e compreensão de uma determinada realidade existencial pertinente ao campo das Ciências Humanas e Sociais Aplicadas, uma vez que faz emergir concepções, discursos, reflexões e significados sobre diferentes fenômenos resultantes de experiências e relações concretas vivenciadas pelos sujeitos sociais no cotidiano.
\end{abstract}

Palavras-chave: Representações sociais. Pesquisa científica. Ciências Humanas. Ciências Sociais Aplicadas.

\begin{abstract}
This article main objective is to reflect on Serge Moscovici Social Representations Theory (SRT) as a didactic-methodological reference of research in the field of Applied Social and Human Sciences. To achieve this, first some general conceptual definitions that gravitate around the word representation(s) are presented, as well as a brief overview of the of Social Representations Theory. Then, the structural approach (or core) of Jean-Claude Abric as a theoretical and methodological support of social representations is commented. Finally, questions concerning the use of Social Representations Theory in the development of scientific
\end{abstract}

\footnotetext{
* Mestre em Educação pela Universidade Estadual de Ponta Grossa (UEPG). Licenciado em Pedagogia pelo Centro Universitário Campus de Andrade (UNIANDRADE). Professor Adjunto da Faculdade Sagrada Família (FASF), junto a cursos de graduação (bacharelado/ licenciatura) e pós-graduação lato sensu. Ponta Grossa, Paraná, Brasil. E-mail: mestrepedago@yahoo.com.br
} 
research and its importance nowadays are brought to discussion. The study showed, at last, that the Social Representations Theory appears as an important teaching and methodological tool to scientific research and understanding of a particular existential reality relevant to the field of Applied Social and Human Sciences, once it brings out conceptions, speeches and reflections about different meanings and phenomena resulting from experience and relationships experienced by concrete social subjects in everyday life.

Keywords: Social representations. Scientific research. Humanities. Applied Social Sciences.

Recebido em: 11/11/2011. Aceito em: 20/11/2012.

\section{Introdução}

Pesquisar um determinado fato, fenômeno ou acontecimento social é, por excelência, uma tarefa deveras complexa, visto que são muitos os fatores de ordem estrutural, didática, pedagógica e metodológica envolvidos. No entanto, essa atividade de pesquisa torna-se ainda muito mais desafiante quando o pesquisador tem a intenção de procurar compreender o conjunto de opiniões, crenças ou valores que são socialmente construídos em grupos delimitados no que diz respeito a um determinado objeto de investigação, como uma estratégia particular de apropriação dos grupos para orientar e/ou justificar as tomadas de decisão em relação a esse objeto.

Visando auxiliar o trabalho do profissional pesquisador acerca dessas questões e de outras similares, desponta a Teoria das Representações Sociais (TRS) como um referencial didático-metodológico de pesquisa extremamente útil - em particular, ao campo das Ciências Humanas e Sociais Aplicadas.

Trazer à tona algumas discussões e reflexões sobre possibilidades, limitações e desafios desse aporte teórico e didático-metodológico de pesquisa científica para a área das Ciências Humanas e Sociais Aplicadas constitui, pois, o principal objetivo do presente artigo.

Este estudo se encontra estruturado em cinco partes distintas, buscando apresentar: definições conceituais referentes ao termo representação(ões), apontamentos acerca da abordagem estrutural como suporte teórico e metodológico das representações sociais, além de uma breve visão panorâmica da Teoria das Representações Sociais; bem como sua utiliza- ção no desenvolvimento de pesquisas científicas e sua importância na atualidade. À guisa de considerações finais, retomamos alguns aspectos centrais do trabalho, o qual não se esgota por completo. Está, portanto, aberto a novos questionamentos por parte de estudiosos e pesquisadores que reconhecem o valor heurístico das Representações Sociais, especialmente no que tange às suas condições de produção, aos processos de circulação e a seu estatuto epistemológico nos ambientes acadêmicos brasileiros.

Vale destacar ainda que, neste artigo, optamos por adotar uma abordagem qualitativa de pesquisa, haja vista que esta metodologia enfatiza mais o processo do que o produto, tendo a preocupação de retratar a realidade tal qual como ela se apresenta. Envolve a obtenção de dados descritivos, o que significa, na concepção de Pacheco (1995), que o objeto de estudo não é constituído apenas pelo comportamento, mas também pelas intenções do pesquisador e situações por ele vivenciadas. Mais do que a procura de relações entre processo e produto, buscou-se, dessa forma, efetuar uma análise interpretativa e crítico-reflexiva da temática de investigação e de sua influência na interação didática.

Nesse sentido, a tipologia de pesquisa que norteou as discussões aqui apresentadas foi a de cunho descritivo-exploratória analítica, uma vez que esta "observa, registra, analisa e correlaciona fatos (variáveis) sem manipulá-los, procurando assim descobrir, com precisão, a frequência com que um fenômeno ocorre, através de sua relação/conexão com outros" (PÁDUA, 1996, p. 49). Essa tipologia de pesquisa também possibilita a descrição exata dos acontecimentos 
da realidade e a intervenção do pesquisador sobre a mesma na tentativa de transformá-la.

Para que fosse possível obter uma visão geral acerca do objeto de investigação, buscamos realizar um minucioso levantamento do arcabouço teórico existente, recorrendo, portanto, a livros, artigos científicos, dissertações de mestrado e teses de doutorado, a fim de obter informações úteis, relevantes e significativas à pesquisa em questão.

\section{Representação(ões): algumas definições conceituais}

Para que se possa melhor compreender os propósitos da Teoria das Representações Sociais no campo das Ciências Sociais Aplicadas, é necessário, inicialmente, elucidar alguns significados expressos pelo termo representação.

Segundo Bunge (2002, p. 343), representação pode ser definida, em linhas gerais, como uma "tradução conceitual, visual, auditiva ou artifatual de um objeto (material ou ideal), isto é, uma operação pela qual a mente humana tem presente em si mesma uma imagem mental, uma ideia ou um conceito correspondendo a um objeto externo".

Por estar diretamente atrelada aos vocábulos “ideia", "conceito", "entendimento", "imagem", "juízo" ou "opinião", a palavra "representação" é aplicada também com relação às Artes Cênicas, no sentido de "desempenho de um papel" ou ainda de "tomar o lugar de alguém", como no caso de imperadores que, até o século XVIII, eram considerados representantes divinos - ou em regimes democráticos de governo, em que presidentes, senadores, deputados e vereadores são eleitos a partir do voto popular secreto no intuito de serem os legítimos "representantes" dos cidadãos em decisões políticas.

Ao longo da história da civilização humana, o conceito de "representação" tem sido alvo de estudos e debates por parte de diferentes pensadores, principalmente nos campos da Filosofia e da Sociologia, a exemplo do sociólogo Émile Durkheim (1858-1917), o qual, preocupado em analisar as questões da sociedade em geral, e, particularmente, da moral, partiu das representações individuais e, por analogia, chegou ao entendimento de que a sociedade convive com fenômeno semelhante. Para Alevato (1999, p.
87-88), isso significa dizer que:

As representações individuais constituem-se em algo novo e não são apenas soma de imagens e ideias retidas pela memória. Ao experimentarmos uma sensação, por exemplo, esta não cai num vazio, esgotando-se em si mesma. Ao contrário. Relaciona-se imediatamente com outras representações, desencadeando um processo mais amplo, pelo qual o indivíduo será capaz de interpretar a mensagem recebida, mobilizando corpo e espírito, a fim de construir assim novas representações.

A interpretação das representações individuais encontra-se embasada no estudo da chamada "Sociologia do Conhecimento", uma espécie de sub-disciplina sociológica que se ocupa de tudo aquilo que passa por "conhecimento" em uma sociedade, independentemente da validade ou invalidade última do mesmo, por quaisquer critérios (BERGER; LUCKMANN, 2002). Pode-se afirmar que o conceito de representação está relacionado à objetivação da realidade, à teoria das instituições e à questão da legitimação e dos papéis sociais. Observa-se, assim, que esse conceito parte da concepção de Durkheim, mas ganha um alcance mais amplo, dado que são de perspectivas epistemológicas notadamente distintas.

\section{Teoria das representações sociais: uma breve visão panorâmica}

O fenômeno da apropriação dos conhecimentos pelo senso comum foi estudado por Serge Moscovici em sua obra intitulada La psycanályse son image et son public, apresentada em primeira edição no ano de 1961. Com esse estudo, Moscovici (1978) inaugurou uma nova postura epistemológica ao afirmar que a absorção da ciência pelo senso comum não é, como geralmente se defendia, uma vulgarização do saber científico; ao contrário, trata-se de um tipo de conhecimento adaptado a outras necessidades, obedecendo a determinados critérios e contextos específicos.

Ao situar a Psicologia Social na encruzilhada entre a Psicologia e as Ciências Sociais, partindo do conceito de representações (coletivas), de Durkheim, e dele se distinguindo, Moscovici renova o modo tradicional de análise da sociedade capitalista, insistindo na especificidade 
dos fenômenos representativos que ocorrem nas sociedades contemporâneas e que se caracterizam pela intensidade e pela fluidez das trocas e comunicações, pelo desenvolvimento da ciência e a mobilidade social. Isso permite ao autor cunhar a Teoria das Representações Sociais (TRS) como uma concepção teóricometodológica de pesquisa no campo das Ciências Sociais Aplicadas, e que, desde o final da década de 1980, vem se difundindo amplamente nos espaços acadêmicos brasileiros.

Partindo do princípio de que "toda representação é de alguém tanto quanto de alguma coisa, configurando-se como uma forma de conhecimento por meio da qual aquele que conhece se substitui no que é conhecido" (MOSCOVICI, 2003, p. 11); entende-se Representação Social como uma teoria ou ciência coletiva destinada à interpretação e à intervenção no real, indo além do que é imediatamente dado na Filosofia e na Sociologia acerca da classificação de eventos e fatos sociais.

Em outras palavras, as representações sociais seriam verdadeiras teorias do senso comum que se elaboram coletivamente nas interações sociais sujeito-sujeito e sujeito-instituição, num determinado tempo, em uma cultura e espaço próprios, na tentativa de tornar o estranho familiar e dar conta do real.

Tendo em vista que no processo de interação social o sujeito elabora o conhecimento, vai se socializando e (re)construindo valores e ideias que circulam na sociedade de modo bastante amplo, concordamos com Spink (1993) quando ele afirma que as representações sociais se constituem no cotidiano e fazem parte da realidade das pessoas, se estruturam e conduzem o comportamento de um indivíduo e a comunicação que se estabelece entre ele e os demais membros da sociedade. Em suma: as "representações sociais são uma forma de conhecimento, socialmente elaborada e partilhada, com um objetivo prático, e que contribui para a construção de uma realidade comum a um determinado conjunto social" (JODELET, 2001, p. 32).

Em face dessa argumentação, evidencia-se o fato de que a linguagem possui um papel fundamental no contexto das representações sociais, uma vez que é devido ao grau de importância dado à linguagem que se viabiliza a construção, pelo sujeito e pelos grupos sociais, do sentido de cada um dos objetos do seu entorno, refletindo assim sua própria condição psicossocial e histórica como parte de uma dada realidade e totalidade social existente.

A partir da Teoria das Representações Sociais, é passível de se questionar, portanto, a natureza pela qual os conhecimentos são (re) construídos. Por outro lado, também se torna possível a visualização da relação dos indivíduos com a sociedade, tornando-se também viável o desvelamento da teia de significados que sustentam o cotidiano, sem a qual a sociedade não existiria. Dessa forma, pode-se afirmar seguramente que o homem se constrói ao mesmo tempo que está construindo o mundo ao seu redor. Dizemos isso porque entendemos que as representações são essencialmente dinâmicas e produtos de determinações tanto históricas quanto do aqui-e-agora, bem como construções que têm uma função precípua de orientação dos conhecimentos sociais que situam o indivíduo no mundo - e que, situando-o, definem sua identidade social, ou seja, o seu modo de ser particular, processo-produto de seu ser social histórico.

Nesse contexto, o interesse da Psicologia Social ultrapassa as perguntas "o que" é determinado fenômeno social e "como" ele é conhecido, para se questionar sobre quem conhece e de onde, visto que:

Na perspectiva moscoviciana, as representações são campos estruturados pelo habitus e pelos conteúdos históricos que impregnam o imaginário social, seja porque são fatores estruturantes desse contexto e, como tal, motores de mudança social; seja porque são teorias do senso comum configuradas pelos conhecimentos acadêmicos que se relacionam com os conhecimentos populares, utilizadas para a compreensão da realidade social. Os conhecimentos de senso comum, dos universos consensuais, agregam parcelas do conhecimento erudito produzido nos universos reificados compostos pela Academia, os quais são modificados, fazendo com que se originem as representações de determinado grupo ou indivíduo (SANTOS, 2006, p. 262). 


\section{A abordagem estrutural como suporte teórico e metodológico das representações sociais}

Considerando-se que as representações sociais são modalidades de pensamento prático orientadas para a comunicação, a compreensão e o domínio do ambiente social, material e ideal, onde os indivíduos lançam mão das teorias do senso comum para internalizar o novo a partir de seus conceitos preexistentes e nortear suas práticas, tornando familiar o que não o é (BOURGUIGNON, 2001), pode-se observar que, no processo de construção de uma representação social, em que um objeto a ser processado mentalmente pelo sujeito provoca mudanças e é alterado, existem basicamente dois conceitos determinantes subjacentes: a objetivação e a ancoragem.

Se objetivação e ancoragem dizem respeito aos processos de formação das representações sociais, a Teoria da Abordagem Estrutural (ou Teoria do Núcleo Central) das Representações Sociais, de Jean-Claude Abric, procura explicar a estruturação de tais conhecimentos.

Na concepção de Abric (1998, p. 32), uma representação social é organizada em torno de dois subsistemas - central e periférico -, de modo que nesse arranjo "o sistema central, que pode ser composto por um ou mais elementos, dá a significação da representação social; ao passo que o sistema periférico dá sustentação a essa base, configurando-se como um componente estruturante".

Uma vez que os elementos do núcleo central tendem a se apresentar como funcionais e normativos, fazendo que o mesmo tenha uma função relevante para a representação social, organizando as significações e prescrevendo ações para que a representação seja mantida, Alves-Mazzotti (2007, p. 582) chama a atenção para o fato de que:

O núcleo central desempenha ainda três papéis essenciais: (a) uma função geradora - ele é o elemento pelo qual se cria e se transforma uma representação; (b) uma função organizadora - é ele que determina a natureza das ligações entre os elementos de uma representação; e (c) uma função estabilizadora - seus elementos são os que mais resistem à mudança. Por sua vez, os elemen- tos do subsistema periférico têm também três funções principais, quais sejam: (i) ser a interface entre o núcleo central e o contexto; (ii) adaptar as representações diante das mudanças do meio; e (iii) preservar a representação.

Em outros termos, isso significa assegurar que no subsistema periférico das representações sociais é possível que exista a presença de elementos históricos relativos ao indivíduo e que, consequentemente, estes atuem na constituição desse subsistema, caracterizando assim uma maior heterogeneidade dos conceitos em relação ao grupo.

A análise de uma representação social, permeada por diferentes saberes, crenças e valores relacionados com aspectos cognitivos e sociais, não se dá a conhecer de modo muito simples. Em decorrência disso, a abordagem estrutural das representações sociais abriga distintos métodos de pesquisa e instrumentos de coleta de dados, sendo possível a utilização de um viés plurimetodológico das representações, conforme proposto por Abric (1998). Convém salientar que esse método de pesquisa científica, muito útil no campo das Ciências da Educação e das Ciências Sociais Aplicadas, com o devido suporte da Teoria das Representações Sociais, agrega aspectos de ordem qualitativa e quantitativa, configurando um modelo misto de pesquisa: a chamada pesquisa do tipo qualiquantitativa.

Diante do exposto, pode-se dizer, resumidamente, que a Teoria da Abordagem Estrutural propõe que os elementos da representação sejam organizados em um núcleo central, no qual toda a representação social é organizada e unificada, dando sentido ao conjunto das representações. Entretanto, em volta desse núcleo existem componentes periféricos que contribuem significativamente para clarificar o caminho conceitual, teórico, didático e metodológico do estudo das representações sociais. Assim, o fator determinante do(s) elemento(s) que constitui(em) esse núcleo central depende exclusivamente da natureza do objeto de investigação e da relação que o grupo social mantém com o mesmo. 


\section{Utilização da teoria das representações sociais no desenvolvimento de pesquisas científicas}

Sá (1998) afirma que, por valorizar amplamente o conhecimento empírico e a interação entre os indivíduos e o meio social, a Teoria das Representações Sociais provocou uma ruptura com os parâmetros orientadores da Psicologia Social e, talvez por esse motivo, tenha enfrentado muita resistência nos ambientes acadêmicos, permanecendo assim desprestigiada durante um longo período.

No entanto, desde o período entre o final dos anos 1980 e início da década de 1990, principalmente devido aos abalos vividos pela tradição positivista e cartesiana, a Teoria das Representações Sociais vem oferecendo, principalmente ao campo das Ciências Sociais Aplicadas e à área educacional, novas possibilidades para trabalhar com a diversidade social e a complexidade da educação e do contexto escolar na sociedade contemporânea. Assim, constitui-se como um valioso referencial teórico e didático-metodológico para o desenvolvimento de estudos e pesquisas científicas em diferentes domínios do saber, tais como História, Filosofia, Psicologia, Sociologia, Antropologia e Medicina, entre outros.

De acordo com Siqueira (2010, p. 89), sua principal contribuição reside na "compreensão da formação e consolidação de conceitos construídos e veiculados pelos sujeitos sociais". Além desse fator, convém destacar a importância da noção de representação social para a compreensão dos fenômenos educacionais, não apenas numa perspectiva macroscópica, mas também para análises mais detalhadas de aspectos que envolvem o cotidiano escolar: docentes, discentes, práticas pedagógicas, instituições educacionais, saberes escolares, conhecimentos científicos, relações interpessoais etc.

Em linhas gerais, concebe-se a ideia de que o crescente número de pesquisas científicas fundamentadas basicamente na Teoria das Representações Sociais pode ser decorrente de dois fatores centrais, que não podem ser considerados de forma isolada: $1^{\circ}$ ) o desenvolvimento e a solidificação dessa teoria como aporte teórico-metodológico; e $2^{\circ}$ ) a crise de paradigmas científicos que colocou em discussão a tradição científica cartesiana como método infalível de compreensão da realidade até então predominante nas pesquisas nesse campo (GILLY, 2001).

Esse referencial didático e metodológico vem se consolidando amplamente no Brasil contemporâneo. Entre outros, destacam-se Moscovici, Jodelet, Abric, Flament e Wagner como autores representativos da Teoria das Representações Sociais. Entretanto, conforme afirma Sá (1998), Jodelet é quem mais se destaca, devido ao amplo programa de cooperação que mantém com a América Latina.

Grosso modo, pode-se dizer que a Teoria das Representações Sociais se consolida no Brasil em decorrência, entre outros fatores: da criação de grupos de estudos e pesquisas, principalmente junto aos programas de pós-graduação stricto sensu (mestrados e doutorados); do intercâmbio e da colaboração de pesquisadores estrangeiros como Jodelet, Wagner e o próprio Moscovici; da existência de uma rede internacional de comunicação sobre representações sociais; e dos debates e das trocas de experiências entre esses grupos de estudos e pesquisas em eventos científicos, nacionais e internacionais, acerca da Teoria das Representações Sociais.

À guisa de exemplificação, podemos citar o caso da região nordeste brasileira, onde, a cada dois anos, acontecem Encontros Regionais de Estudos e Pesquisas sobre Representações Sociais. Também convém mencionar as Jornadas Internacionais de Representações Sociais (JIRS) que vêm sendo realizadas sistematicamente no Brasil, constituindo-se como um dos espaços privilegiados para divulgação e socialização de pesquisas científicas no campo das Representações Sociais. Trata-se de um evento científico bianual que reúne profissionais pesquisadores de diversos países da Europa e da América Latina e também de diferentes Estados brasileiros. Até o presente momento, já foram realizadas cinco Jornadas, a saber: a primeira ocorreu em Natal-RN (1998), a segunda em Florianópolis-SC (2001), a terceira no Rio de Janeiro-RJ (2003), a quarta em João Pessoa-PB (2005), e a última em Brasília-DF (2007).

Para Camargo (2005, p. 34), "esses eventos científicos têm crescido substancialmente a cada ano, visto que é cada vez maior o número de trabalhos de pesquisa e estudiosos da Teoria das Representações Sociais". Segundo o autor, 
o acentuado ritmo de desenvolvimento desse campo de estudos no Brasil dá-se não só no âmbito da Psicologia Social e nas áreas afins. Tal impulso tem levado a produção científica brasileira a contribuir significativamente para o debate acadêmico, tornando-a reconhecida por renomados pesquisadores europeus e latinoamericanos. É interessante salientar ainda que ao longo de todos esses eventos científicos a Educação aparece como um domínio de estudo sempre presente e em crescente expansão, sendo, inclusive, um dos maiores Grupos de Trabalho e Discussão (GTD) nas JIRS.

Com base na análise dos resumos de trabalhos científicos constantes nos Anais da quinta e última Jornada Internacional sobre Representações Sociais, sediada em Brasília-DF no ano de 2007, pode-se identificar que, em relação ao campo educacional, as principais pesquisas que vêm sendo desenvolvidas à luz da Teoria das Representações Sociais estão exclusivamente voltadas para a formação de professores, abordando as temáticas "formação continuada" e "profissão docente" (objetos de representação social), embora apresentem certa variabilidade no que diz respeito à abordagem metodológica, à categorização temática e ao grau de relevância do tema de pesquisa em cada país ou região.

Estando diretamente relacionadas aos termos "ideia", "conceito", "entendimento", "imagem", "juízo" ou "opinião" correspondente a um objeto (material ou ideal) externo, as representações sociais apresentam, em sua essência, um viés etnográfico de pesquisa no campo das $\mathrm{Ci}$ ências Humanas e Sociais Aplicadas, utilizando dados quantitativos e qualitativos notadamente relevantes e significativos para o desenvolvimento da mesma.

Mas, o que é etnografia?

Segundo Erickson (2000), a palavra "etnografia" é de origem grega e significa "escrever sobre (o outro)". O termo surgiu no final do século $\mathrm{XIX}$, quando antropólogos, sociólogos e demais estudiosos de áreas afins passaram a mostrar o modo de vida de outros povos, em geral "primitivos", sob a forma de relatos escritos. Até muito recentemente, as técnicas etnográficas de pesquisa científica eram utilizadas quase exclusivamente por cientistas do campo das Ciências Sociais Aplicadas. Entretanto, no início da década de 1970, pesquisadores da área de
Ciências Humanas e Educação também começaram a fazer uso dessas técnicas, logrando notável êxito.

É interessante destacar que a pesquisa etnográfica requer, entre outros fatores, observação participante, embora o observador/pesquisador deva tomar certa distância daquilo que Ihe é óbvio e familiar no cotidiano e assim olhar os acontecimentos de investigação como "estranhos", tentando desvendar o que se oculta por trás das ações sociais e que, frequentemente, não é percebido pelos atores/sujeitos envolvidos na pesquisa (LÜDKE; ANDRÉ, 1986).

Sabe-se que, em geral, o observador - como participante presente em lugares e momentos específicos no local de pesquisa tende a esperar que tipos pontuais de eventos recorrentes aconteçam continuamente. É necessário, sobretudo, atentar para o fato de que o ponto mais central da observação participante é a oportunidade de o pesquisador aprender por meio da participação ativa, testando assim seu aporte teórico e experimentando diferentes tipos de participação no contexto investigado. Dizemos isso, porque entendemos que o papel do observador, na condição de participante, configura-se, inclusive, como um papel em que a identidade do pesquisador e os objetivos do estudo investigativo devem ser revelados ao grupo pesquisado (informantes) desde o início do desenvolvimento da pesquisa de campo, a fim de esclarecer possíveis dúvidas decorrentes de sua atuação.

\section{Importância da teoria das representações sociais na atualidade: apontamentos gerais}

No âmbito das Ciências Humanas e das Ciências Sociais Aplicadas, tem sido cada vez mais crescente o número de estudos e pesquisas científicas que apontam para a natureza de um objeto de investigação "novo" e instigante: as Representações Sociais. Estudam-se, pois, objetos específicos e que fazem parte da intervenção profissional - porém, considerando a percepção que os sujeitos informantes possuem acerca de questões pertinentes a esses objetos de pesquisa.

As pesquisas desenvolvidas no campo da chamada "Sociologia do Conhecimento" e das Representações Sociais têm demonstrado que 
não basta apenas analisar os fenômenos sociais em sua dimensão quantitativa, bem como é insuficiente contextualizar, em termos históricos, as suas determinações. O fenômeno social analisado exige, para sua melhor compreensão, que se vá além, isto é, que se investigue de forma crítica e reflexiva quais representações os participantes das pesquisas de campo constroem sobre ele. Além disso, as pesquisas científicas também requerem um diálogo entre as diferentes áreas do conhecimento, a fim de abordar o objeto de estudo sob diversos pontos de vista e perspectivas, buscando dar-Ihe o tão necessário sentido de totalidade.

No prefácio à obra intitulada Núcleo central das representações sociais, de Celso Pereira Sá (1996), encontra-se uma afirmação bastante enfática sobre a importância do estudo da temática "Representações Sociais" na atualidade:

[...] Isto porque, para além das tomadas de posição ideológicas, a análise científica das mentalidades e práticas sociais será um dos elementos indispensáveis à evolução e ao progresso social. Nesse sentido, a Teoria das Representações Sociais constitui, hoje, um sistema teórico particularmente importante para atingir esse objetivo, pois uma das vantagens da perspectiva das Representações Sociais é que ela se nutre de abordagens diversas e complementares: estruturais, por certo, mas igualmente etnólogas e antropológicas, sociológicas e históricas (ABRIC, 1996, p. 9-10).

Não se pode negar, pois, que atualmente a Teoria das Representações Sociais encontra-se no centro de um debate interdisciplinar acadêmico, ampliando as possibilidades de compreensão das relações entre os diferentes tipos de conhecimento e as práticas sociais que lhes dão origem. Todavia, exige-se que essa tipologia de produção de conhecimentos científicos estabeleça um diálogo aberto e permanente entre diferentes fundamentos teóricos e procedimentos didático-metodológicos.

Considerando o grau de complexidade que envolve a natureza das Representações Sociais, cabe à investigação científica descrevê-las e analisá-las em todas as suas dimensões. Sobre essa questão, Jodelet (2001, p. 41-42) informa que os principais eixos necessários à compre- ensão da multidimensionalidade da Teoria das Representações Sociais dizem respeito ao fato de que:

$\left.1^{\circ}\right)$ a representação social é sempre representativa de alguma coisa (objeto) e de alguém (sujeito);

$2^{\circ}$ ) as representações sociais envolvem uma atividade de simbolização do objeto e de sua interpretação, dando-lhe significados, que nada mais são que as construções cognitivas dos sujeitos sociais;

$3^{\circ}$ ) o estudo das representações sociais deve envolver todos os aspectos que demonstrem o grau de pertença dos sujeitos a um grupo social e como os mesmos participam da vida em sociedade e que cultura expressam;

$\left.4^{\circ}\right)$ as representações sociais se apoiam em suportes linguísticos e em comportamentos que dão forma ao objeto e o caracterizam;

$5^{\circ}$ ) trata-se de um saber prático, que se refere à experiência social dos sujeitos;

$\left.6^{\circ}\right)$ sinteticamente, analisar as representações significa responder a indagações como: quem sabe e de onde sabe? o que sabe e como sabe? sobre o que sabe e com que efeito? Ou seja, compreendê-las a partir das condições de sua produção e circulação, de seus processos, de suas etapas e de seu estatuto epistemológico.

Em outras palavras, isso significa dizer que as Representações Sociais fazem uma ponte entre o conhecimento de senso comum e o científico, na medida em que é um sistema de acolhida das informações que circulam no meio social, concretizadas através das experiências dos sujeitos sociais envolvidos e dos processos de comunicação existentes. Por ser assim, tem uma carga emocional muito grande, o que facilita as trocas e partilhas entre diferentes indivíduos, grupos e comunidades sociais.

As Representações Sociais expressam, enfim, a forma como cada grupo social se organiza e constrói seus significados, através de interações dinâmicas e determinadas historicamente. Nesse contexto, "as representações são 
sociais porque se trata de um esforço coletivo de construção de conhecimentos que permite a indivíduos, grupos e comunidades trabalhar com situações e fenômenos que fazem parte de sua realidade cotidiana" (GOFFMAN, 1983, p. 74). Assim, qualificar uma representação como "social" equivale a optar pela hipótese de que ela é produzida e engendrada coletivamente.

Mais importante que saber quem é o sujeito que produz as representações sociais, é saber por que se produzem tais representações, a que funções correspondem e quais condutas e orientações sociais resultam, compondo assim um quadro complexo que as qualifica. Tudo isso incita o pesquisador a se preocupar com as múltiplas dimensões que os significados atribuídos pelos sujeitos à sua realidade social podem apresentar, cujo potencial está em mobilizar e transformar relações sociais. Esse desafio também se coloca, de modo muito particular, às Ciências Humanas e Sociais Aplicadas.

Sem a pretensão de esgotar o assunto em questão, vale enfatizar ainda que a Teoria das Representações Sociais apresenta possibilidades múltiplas de investigar um mundo permeado de "sinais", "símbolos" e "linguagens" que expressam diferentes formas de interpretar uma mesma realidade, bem como de revelar as formas pelas quais os sujeitos sociais se apropriam de sua própria realidade social, dando assim aos pesquisadores e estudiosos dessa temática pistas acerca da natureza das relações sociais em geral. É importante apreender o pensamento dos sujeitos, dos grupos e das coletividades sociais sobre os objetos de sua intervenção e de suas relações, uma vez que as Representações Sociais têm desempenhado importante função na comunicação entre eles e na formação de opiniões, comportamentos e atitudes frente às inúmeras exigências da nova realidade existencial social do século XXI.

No entanto, estudos desenvolvidos por Camargo (2005) revelam a necessidade de atentar para o fato do que se pesquisa em relação às Representações Sociais no campo das Ciências Humanas e Sociais Aplicadas na atualidade, e de como se faz isso, levando-se em consideração os ranços e as possibilidades de natureza didático-metodológica presentes nas produções acadêmico-científicas já realizadas e em desenvolvimento.
Em linhas gerais, os fatores que indicam significativos avanços na utilização da Teoria das Representações Sociais como aporte teórico de pesquisas científicas em Educação e Ciências Sociais Aplicadas são: a consolidação dessa teoria nos ambientes acadêmicos e centros de pesquisa científica em quase todo território nacional e internacional; o fato de os objetos de pesquisa das Ciências Humanas e Sociais Aplicadas estarem sendo estudados numa perspectiva que abre espaço para explicitação do simbólico e dos significados sócio-culturais a eles atribuídos pelos sujeitos sociais; a versatilidade e a consistência dos percursos das investigações científicas nessas duas áreas do saber, abrindo assim leques para a combinação e o cruzamento das representações sociais por diferentes métodos e técnicas de pesquisa científica; e a credibilidade que os estudos em representações sociais começam a conquistar junto a outros campos de conhecimento.

Por outro lado, como elementos limitadores das representações sociais no desenvolvimento de pesquisas científicas, pode-se citar alguns fatores: a falta de maior clareza na definição de quais objetos sociais são notadamente estudados no âmbito da Educação e das Ciências Sociais Aplicadas, dada a diversidade de temáticas existentes, e as lacunas em relação à indicação do itinerário metodológico das pesquisas, ou seja, como se chegou às representações sociais. Note-se que seus conceitos teóricos têm dialogado muito pouco com os dados empíricos coletados, resumindo-se, pois, na apresentação de meras descrições de resultados denominados "representações sociais", com pouquíssimos elementos que de fato evidenciem sua real presença.

Embora a Teoria das Representações Sociais apresente alguns ranços ao desenvolvimento de certos tipos de pesquisa científica, não se pode negar o fato de que as representações sociais têm a linguagem como mediação privilegiada, configurando-se num importante conceito para se pensar a relação estabelecida entre pesquisador e informantes num determinado contexto da realidade existencial investigada.

De forma simplificada, pode-se dizer que as representações sociais seriam uma espécie de "tijolaços de saber", isto é, porções de conhecimentos, costumes, tradições e memórias que 
encontramos em todas as sociedades - elementos extremamente importantes para a compreensão de um povo. Dito de outra forma, "as representações sociais são modos de conhecimentos do senso comum, compartilhados socialmente, que surgem e se legitimam no cotidiano e têm como objetivo principal compreender e controlar a realidade social" (DUVEEN, 1995, p. 30).

Diferentemente do conhecimento científico que é reificado e cognitivo por excelência, as representações sociais, como conhecimento do senso comum, podem apresentar algumas contradições, fragmentações ou ambivalências em sua superfície. Mas, na condição de campo representacional, apresentam um núcleo fundamentador mais estável e permanente, baseado na cultura e memória da sociedade.

Nesse sentido, concordamos com Moscovici (1978), quando este defende a ideia de que as pessoas ou grupos sociais não são receptores passivos, "tábulas rasas", nessa relação, mas integrantes ativos, participantes, elaboradores de um pensamento social que constantemente é reavaliado para a resolução de problemas e conflitos, sendo essa ressignificação uma alternativa mais simples de compreensão, ao menos pela lógica não científica.

$\mathrm{E}$, face dessas questões, torna-se profícuo salientar também que em vários estudos científicos as mídias em geral vêm sendo apontadas como uma das principais instâncias criadoras e propulsoras de representações sobre os mais diversos e polêmicos assuntos, que acabam direta ou indiretamente por fundamentar grande parte das ações humanas cotidianas. Sumariamente, pode-se dizer que as representações sociais estão presentes tanto nas mídias quanto nas mentes dos sujeitos sociais.

Assim, entendemos que a Teoria das Representações Sociais, como referencial didático-metodológico de pesquisa científica no campo das Ciências Humanas e Sociais Aplicadas, deve servir como importante ferramenta para descrição, análise, interpretação e reflexão crítica acerca dos diferentes modos de organização social do pensamento humano, da produção e da disseminação de valores culturais e sociais que se legitimam diariamente e são compartilhados na sociedade contemporânea. Isso deve ser feito a fim de torná-la um pouco mais justa, equânime, ética e democrática.
É possível construir esse tipo de sociedade almejada, uma vez que a representação social toma como principal ponto de partida a diversidade dos sujeitos sociais, das atitudes e dos fenômenos em toda sua "'estranheza", impondo-Ihe visibilidade. Deve-se ter em vista que a representação social tem por objetivo central descobrir como os indivíduos e grupos sociais podem trabalhar na construção de um mundo estável e previsível, a partir de sua múltipla diversidade cultural, política, ética, moral, religiosa, econômica e social.

Por todos esses fatores, atualmente considera-se que as Representações Sociais constituem uma teoria concebida para responder a questões específicas, com respeito a crenças e vínculos sociais, e também para descobrir novos fenômenos. Em outras palavras, isto implica afirmar que, por um lado, a Teoria das Representações Sociais está interessada em situações de interação social e, por outro, pelo conhecimento social e as diferentes formas de comunicação e uso de linguagens.

É fato que "a Teoria das Representações Sociais busca identificar o conteúdo do conhecimento de senso comum e olhar os modos como ele se expressa na linguagem e comunicação" (JODELET, 2005, p. 93). Nesse contexto, convém observar que, quando se estuda o senso comum, isto é, o conhecimento popular, estuda-se algo que liga sociedade, ou indivíduos, à sua cultura, à sua linguagem, a seu mundo familiar. Logo, as representações sociais constituem um sistema de valores, noções e práticas que asseguram a comunicação entre os membros de uma determinada comunidade.

O processo de comunicação social é condição determinante na formação do pensamento e da representação social como conhecimento. Com a Teoria das Representações Sociais, colocou-se em pauta o senso comum, deixando-se de vê-lo como formas confusas e fragmentadas de conhecimento, uma vez que ele permite a apropriação do conhecimento científico pela sociedade, porém não implica a corrupção e a distorção desse conhecimento. Implica apenas a contextualização na linguagem e a compreensão da sociedade e dos elementos que lhe são peculiares, reais e simbólicos.

Considerando-se que as Representações Sociais realizam a difusão de saber científico 
inédito, transformando-o numa forma de conhecimento socialmente elaborado e partilhado como saber prático de senso comum acessível ao entendimento de todas as pessoas, entendemos ser necessário considerar essa teoria como uma maneira específica de compreender e comunicar o que já sabemos, cabendo apenas introduzir ordem e percepções nesse saber. Assim, a representação social passa a adquirir um significado especial que permite sua compreensão na dinâmica do sentido atribuído aos objetos sociais, ou seja, o senso comum atribuído a algo que dá verdadeiro sentido ao conjunto da representação.

Partindo do pressuposto de que o estudo das Representações Sociais requer uma articulação entre o consensual e o heterogêneo, entre o coletivo e o individual, convém enfatizar a necessidade de não se perder a referência de que um objeto, para ter representação, deve possuir uma relação importante com a vida humana e o contexto social. Ou seja, deve englobar recursos humanos, psicológicos, biológicos e sociais que estão norteando um tema específico dentro de sua diversidade. Em nosso caso, em particular, esse objeto social é a pesquisa científica no campo das Ciências Humanas e Sociais Aplicadas.

\section{Considerações finais}

À medida que este artigo ia tomando forma e sentido, fortalecia-se a concepção de que a Teoria das Representações Sociais não só explica os significados de uma determinada realidade objetiva existencial, como também demonstra o grau de pertencimento de um indivíduo ao seu grupo social.

Esse fato denota a necessidade de apreendê-las sempre de forma vinculada ao contexto sócio-histórico e cultural que as engendrou. Dizemos isso porque todas as interações humanas pressupõem representações. Essas interações, que nada mais são que acontecimentos, estão psicologicamente representadas em cada um dos sujeitos sociais. Isso significa assegurar que, uma vez criadas, as representações adquirem vida própria, circulam, se atraem, se repelem e dão oportunidade ao nascimento de novas e diferentes formas de representações sociais.
Além desses fatores, as representações sociais oferecem aos pesquisadores inúmeras possibilidades de compreensão da realidade social, tanto no campo da produção de conhecimentos quanto no aspecto da intervenção junto aos segmentos sociais. Dentre essas possibilidades, podem ser destacadas: o resgate do conhecimento popular, construído num cotidiano de lutas e trabalho pela sobrevivência; o estreitamento das relações de diálogo entre diferentes sujeitos que participam das intervenções e construções teóricas no campo da pesquisa científica; e a realização de intercâmbio entre diversos campos do saber, tais como Psicologia Social, Antropologia, Sociologia, Filosofia, História entre outras áreas afins.

Particularmente na esfera das Ciências Humanas e Sociais Aplicadas, observa-se que o estudo da Teoria das Representações Sociais oportuniza ricas construções, modificações e adaptações teóricas e didático-metodológicas de pesquisa científica, uma vez que faz emergirem concepções, crenças, imagens, visões, reflexões e discursos, enfim, "significados" sobre determinados fenômenos e acontecimentos sociais que resultam de experiências concretas e atuais, vivenciadas no cotidiano, na presente trama das relações e interações sociais. Seguramente, essa possibilidade foge ao tradicional tratamento metodológico dado à realidade existencial pelas Ciências Humanas e pelas Ciências Sociais no paradigma clássico de pesquisa.

Em linhas gerais, conceber a Teoria das Representações Sociais como um importante referencial teórico e didático-metodológico de pesquisa no campo das Ciências Humanas e Sociais Aplicadas constitui compreender essa teoria como uma nova forma de conhecimento, socialmente elaborada e partilhada, com um objetivo prático e definido, que contribui significativamente para a (re)construção de uma realidade concreta comum a um determinado conjunto social mais amplo (JODELET, 2001). Dito de outra forma, isso implica afirmar que as representações sociais são essencialmente dinâmicas, configurando-se como produtos de determinações tanto históricas quanto do aqui-e-agora, e também como construções que têm uma função de orientação. Elas são conhecimentos sociais que situam o indivíduo no mundo e, situando-o, definem sua identidade social, ou seja, seu modo 
de ser particular, processo-produto de seu ser social histórico.

Nesse contexto, entendemos que reverter práticas e concepções arcaicas de pesquisa científica ainda é um desafio a ser enfrentado, dado a complexidade do processo; embora tais mudanças sejam possíveis de ocorrer, mesmo que de forma gradativa. Mas é preciso não desistir e se lembrar sempre de que a história de um povo não se fez e nem se faz de um dia para o outro, mas sim na luta cotidiana e permanente onde se pode construir uma nova história; muito mais participativa, consciente, dinâmica e efetiva.

Espera-se, assim, que este trabalho possa direta ou indiretamente contribuir para o debate, a reflexão e a crítica construtiva acerca do que se pesquisa e de como se pesquisa cientificamente em Ciências Humanas e Sociais Aplicadas a partir da Teoria das Representações Sociais. Isso deve ser feito a fim de que esse método tenha plenas condições de ser agregado como importante instrumento científico, de poder cultural e com potencial transformador.

Todavia, é necessário ir para além do o que e como é conhecido determinado fenômeno social, no intuito de se questionar reflexivamente sobre quem e de onde se conhece. Isso significa dizer que a presente pesquisa não constitui um fim em si mesma, visto que representa apenas um ponto de partida para futuros estudos e pesquisas científicas que possibilitem novas (re) leituras e ações concretas que possam conduzir à ampliação do arcabouço teórico e metodológico concernente às Representações Sociais e, especificamente, à sua aplicação na área de Ciências Humanas e Sociais Aplicadas.

Portanto, é preciso problematizar a tendência à homogeneização de tudo e de todos e, assim, abrir brechas para possíveis deslocamentos e rupturas paradigmáticas. Nesse sentido, acreditamos que se tivermos deixado como legado da leitura deste artigo certo "desconforto", angústia de quem percebe a falta e a necessidade de (se) questionar, bem como certo "des-arranjo", instabilidade de quem sabe que não é depositário de verdades definitivas, que não pode permanecer, de forma inconsequente, na "Torre de Marfim" e que, portanto, é preciso buscar e respeitar as diferenças, teremos realizado nosso maior intento. E teremos a certeza de que cada leitor, com sua experiência de vida pessoal e profissional, reflexão e análise crítica, acrescentará ao menos um pouco à tessitura deste trabalho: novos fios, novos sentidos e novos suplementos de ordem teórico-prática. Isso é, pois, o que almejamos.

\section{Referências}

ABRIC, J. C. Prefácio. In: SÁ, C. P. Núcleo central das representações sociais. Petrópolis: Vozes, p.7-9, 1996.

. A abordagem estrutural das representações sociais. In: MOREIRA, A. S. P.; OLIVEIRA, D. C. (Orgs.). Estudos interdisciplinares em representações sociais. Goiânia: AB Editora, p.27-38, 1998.

ALEVATO, H. M. R. Qualidade: um mito pósmoderno. In: TEVES, N.; RANGEL, M. (Orgs.). Representação social em educação: temas e enfoques contemporâneos de pesquisa. Campinas: Papirus, p.79-114, 1999. (Coleção Magistério: Formação e Trabalho Pedagógico).

ALVES-MAZZOTTI, A. J. Representações da identidade docente: uma contribuição para a formulação de políticas. Revista Ensaio: avaliação de políticas públicas em educação. Rio de Janeiro: Editora da UFRJ, v.15, n.57, p.579-594, out./dez., 2007.

BERGER, P.; LUCKMANN, T. A construção social da realidade: tratado da sociologia do conhecimento. 21.ed. Petrópolis: Vozes, 2002.

BOURGUIGNON, J. A. A pesquisa sobre representações sociais no contexto do Serviço Social. Revista Emancipação. Ponta Grossa: Editora da UEPG, ano 1, n.1, p.77-88, 2001.

BUNGE, M. Dicionário de filosofia. São Paulo: Perspectivas, 2002.

CAMARGO, B. V. A pesquisa em representações sociais no Brasil. Petrópolis: Vozes, 2005.

DUVEEN, G. Crianças enquanto atores sociais: as representações sociais em desenvolvimento. In: GUARESCHI, P. A.; JOVCHELOVITCH, S. (Orgs.). Textos em representações sociais. Petrópolis: Vozes, p.20-43, 1995.

ERICKSON, F. Métodos qualitativos de pesquisa etnográfica. São Paulo: Summus, 2000.

GILLY, M. As representações sociais no campo da educação. In: JODELET, D. (Org.). As representações sociais. Rio de Janeiro: EDUERJ, p.321-341, 2001. 
GOFFMAN, E. A representação do eu na vida cotidiana. Petrópolis: Vozes, 1983.

JODELET, D. Representações sociais: um domínio em expansão. In: JODELET, D. (Org.). As representações sociais. Rio de Janeiro: EDUERJ, p.17-44, 2001.

Loucuras e representações sociais. Petrópolis: Vozes, 2005.

LÜDKE, H. A.; ANDRÉ, M. E. D. A. Pesquisa em educação: abordagens qualitativas. São Paulo: EPU, 1986. (Coleção Temas Básicos de Educação e Ensino).

MOSCOVICI, S. A representação social da psicanálise. Rio de Janeiro: Zahar, 1978.

Representações sociais: investigação em psicologia social. Petrópolis: Vozes, 2003.

PACHECO, J. A. O pensamento e a ação do professor. Portugal: Editora Porto, 1995.

PÁDUA, E. M. M. Metodologia da pesquisa. Campinas: Papirus, 1996.

SÁ, C. P. A construção do objeto de pesquisa em representações sociais. Rio de Janeiro: EDUERJ, 1998.

SANTOS, J. V. V. As representações sociais da educação a distância: uma investigação junto a alunos do ensino superior a distância e presencial. Florianópolis, 2006. 329 f. (Tese de Doutorado Interdisciplinar em Ciências Humanas - Universidade Federal de Santa Catarina). mimeo.

SIQUEIRA, V. L. Representações em educação online: um estudo das 'falas' na perspectiva dos sujeitos aprendizes. Brasília, 2010. 140 f. (Dissertação de Mestrado em Educação - Universidade de Brasília). mimeo.

SPINK, M. J. Apresentação. In: SPINK, M. J. O conhecimento no cotidiano: as representações sociais na perspectiva da psicologia social. São Paulo: Brasiliense, p.7-15, 1993. 